\title{
Análise sistemática das publicações em tecnologia assistiva, acessibilidade e design universal: panorama da produção bibliográfica da revista estudos em design
}

Systematic review of the publications in assistive technology, accessibility and universal design: Panorama of the bibliographic production from the journal 'Estudos em Design

Bruna da Silveira Suris ${ }^{1}$

Heli Meurer ${ }^{2}$ Fabiane Wolff 3 


\section{Resumo}

Este artigo apresenta um estudo que visa a ampliação do entendimento sobre a Tecnologia Assistiva, e demonstra sua recente expansão, fomentada pela Lei de contratação de Deficientes nas Empresas que aproximou a mesma do mundo corporativo, tornando-se uma importante ferramenta no auxílio à inclusão. Juntamente com a Tecnologia Assistiva e demais áreas correlatas, como a Acessibilidade e o Design Universal, as Inovações e Tecnologias são aliadas dos trabalhadores com deficiências e das empresas nas quais eles estão inseridos, pois transformam seu espaço de trabalho em um ponto de apoio e ampliação de suas capacidades e relacionamentos. O objetivo deste artigo é analisar publicações brasileiras para apresentar o panorama geral de produção acadêmica sobre as tendências e terminologias de aplicação da Tecnologia Assistiva. Para isso, realizou-se uma análise sistemática, embasada na Revista Estudos em Design, na qual, foram analisados 137 artigos com publicações entre os anos de 2007 a 2015. A metodologia utilizada foi de cunho descritivo, através de pesquisa bibliográfica e análise sistemática como base para analisar os artigos coletados. A execução consistiu na investigação em base de dados e no uso de critérios para se chegar a uma amostragem final. Encontrou-se somente 4 artigos que tratam de Tecnologia Assis-

\section{Abstract}

This article presents a study aimed at broadening the understanding of Assistive Technology, and demonstrates its recent expansion, fueled by Disabled hiring Law at Companies that approached them to the corporate world, making it an important tool to help the inclusion. Along with assistive technology and other related areas, such as Accessibility and Universal Design, Innovation and Technology are allies of workers with disabilities and companies in which they are inserted, because it transforms the workspace into a point of support and expansion of his capabilities and relationships. The aim of this paper is to analyze Brazilian publications to present the academic research overview on trends and terminologies application of Assistive Technology. For this, was carried out a systematic analysis, based in the journal 'Estudos em Design', which were analyzed 137 published articles between the years 2007-2015. Was used a descriptive method through literature search and systematic analysis as a basis for analyzing the collected articles. The execution consisted in investigation into database and the use of criteria to arrive at a final sample. It was found only four articles dealing with Assistive Technology, Accessibility and Universal Design. The results demonstrated that the terms are still not published. In this way, was intended to encourage research on the 
tiva, Acessibilidade e Design Universal. Os resultados demonstraram que os termos ainda são pouco publicados. Desta forma, pretende-se fomentar a pesquisa sobre os temas abordados e auxiliar na identificação de gaps ainda não explorados.

Palavras-chave: produção bibliográfica, tecnologia assistiva, acessibilidade design universal. topics and assist in identifying gaps unexplored.

Key-words: bibliographic production, assistive technology, accessibility e universal design. 


\section{Introdução}

A questão da inclusão tornou-se desafiadora para as organizações empresariais e também para as instituições de ensino nos últimos anos. Consequentemente, suas operações estão sujeitas a pressões e análises de uma diversa gama de interessados dentro e fora da organização, como prefeituras, agências do governo, a justiça, os trabalhadores e seus familiares, entre outros. Diante do exposto, percebe-se que tais desafios e imposições fazem com que as empresas comecem a considerar com muita seriedade a contratação responsável de Pessoas com Deficiências (PCD's).

A Lei 8213/91 - art. 93 determina que empresas com 100 (cem) ou mais empregados são obrigadas a preencher de $2 \%$ (dois por cento) a $5 \%$ (cinco por cento) dos seus cargos com beneficiários reabilitados ou PCD's. Corrobora com a Lei 8213/91 o Decreto № 5.296/04 (regulamentador da Lei 10.048/00 - que diz respeito à prioridade de atendimento e da Lei 10.098/00 - que estabelece normas e critérios para a promoção da acessibilidade de pessoas portadoras de deficiências e/ou mobilidade reduzida), que descreve no seu capítulo III - Das condições gerais de acessibilidade - o desenho industrial como um termo utilizado para a concepção de espaços, artefatos e produtos que visam atender simultaneamente todas as pessoas, com diferentes características antropométricas e sensoriais, de forma autônoma, segura e confortável, constituindo-se nos elementos ou soluções que compõem a acessibilidade.

Sendo assim, esta pesquisa tem por objetivo caracterizar as publicações brasileiras em Tecnologia Assistiva no âmbito do design com o intuito de identificar as publicações na área. Assim, deseja-se fomentar pesquisas sobre o tema e possibilitar a inserção do Design Universal, como ator principal na integração de todos os colaboradores das empresas, mitigando a percepção de diferenciação e necessidades dos PCD's com relação aos demais trabalhadores. Dentro desta lógica realizou-se uma análise sistemática para coleta de dados, onde, selecionou-se e analisou-se artigos publicados pela Revista Brasileira Estudos em Design, com classificação no Qualis da CAPES na área de Arquitetura e Urbanismo como A2. Essa revista destaca-se como uma das mais significativas vias de produção científica no país em design, sendo assim, justifica-se a escolha da mesma em detrimento de outras.

Este artigo está estruturado da seguinte forma: introdução; objetivos e método, com a apresentação das ferramentas utilizadas para o desenvolvimento da pesquisa; fundamentação teórica, com o estudo dos termos Design, Design Universal, Tecnologia Assistiva, Acessibilidade, Inovação Social e também Leis e Decretos; resultados, onde serão apresentados os dados que foram averiguados; e as considerações finais com o fechamento do artigo.

\section{Objetivos e método}

O presente trabalho tem como objetivo principal obter o panorama geral das publicações acadêmicas em design, nas quais há a utilização e/ou aplicação do termo Tecnologia Assistiva e de suas áreas afins, como a Acessibilidade e o Design Universal. Assim, foram coletados e revisados os artigos nas publicações da Revista Estudos em 
Design entre os anos de 2007 até 2015.

No que diz respeito à metodologia de pesquisa, segundo Lakatos (2010), entende-se por pesquisa, o processo de conhecimento sistêmico de um assunto específico, através da busca de informações que deem subsídio para responder as questões pré-determinadas de um problema definido, ou seja, através de pesquisa pode-se descobrir fatos novos e/ou conhecer a realidade daquilo que se deseja investigar. Já a metodologia define-se por apresentar o caminho e as ferramentas a serem utilizadas durante o processo de elaboração de uma pesquisa. Para o desenvolvimento deste artigo utilizou-se o método de cunho descritivo, onde se faz possível a compreensão do problema de pesquisa ao averiguar dados em fontes primárias e secundárias, usando dessa forma, o procedimento de investigação e pesquisa bibliográfica, na qual o pesquisador apura informações de materiais publicados (GIL, 2010).

A decisão por analisar as publicações da Revista Estudos em Design, através do método de pesquisa da análise sistemática, deve-se ao acesso às informações e pelo prestígio da mesma como uma das mais significativas vias de produção científica no país. Contanto, a pesquisa restringiu-se em analisar apenas trabalhos publicados completos, gratuitos, com publicação nos últimos cinco anos e que possuíssem no título, palavras-chave e no resumo ao menos uma das palavras-chave definidas na busca para este estudo.

Para a realização da análise foram desenvolvidas três etapas. Na primeira foram feitos os downloads dos arquivos disponíveis no site da Revista Estudos em Design desde o ano de 2007 até o ano de 2015. Posteriormente, elaborou-se uma planilha com as seguintes colunas: fonte, volume, ano, autores, instituição de origem, título do trabalho, se havia ocorrência dos termos (Tecnologia Assistiva, Acessibilidade, Design Universal), resumo e palavras-chave. Na segunda etapa, foram criadas tabelas e gráficos indicando os resultados obtidos na presente pesquisa, como forma de meIhor visualização dos dados gerados. Na terceira etapa, foram separadas e organizadas as palavras-chave de todas as publicações analisadas para confecção de tabelas e gráficos que demonstrassem a frequência de repetição das palavras.

\section{Fundamentação teórica}

A presente seção está dividida da seguinte maneira: Design, Design Universal, Tecnologia Assistiva, Acessibilidade e Leis, decretos e requerimentos, a partir de publicações de cada área específica.

\subsection{Design e Design Universal}

Os significados para a etimologia da palavra "Design" são apontados como diversos e até mesmo conflitantes. Para Moura e Gusmão (2008), Design se origina do latim DESIGNO e DE SIGNUM, palavras essas, que ao serem traduzidas podem expressar desde desenhar e idear até marca, imagem e selo. Conforme Faggiani apud Moreira e Costa (2010) sua constituição enquanto prática se verifica, somente a partir do século XIX, com o desenvolvimento da Bauhaus e da Escola da Forma, ao longo do século $X X$, onde o Design enquanto foco de um fazer projetual iria se consolidar. 
Uma área correlata do Design é o Design Universal. O conceito teve início através de um arquiteto norte-americano que se dedicou à questão da Acessibilidade, no qual, o mesmo necessitou do uso de cadeira de rodas durante toda sua vida. O termo tem crescido e com isso, gerado interesse, entre profissionais como designers, engenheiros, arquitetos, paisagistas, entre outros. O Design Universal tem sido aplicado em projetos de ambientes públicos, edifícios e produtos, sempre com o objetivo de produzir artefatos ou serviços, dos quais, a grande maioria das pessoas possa fazer uso. A sua aplicação está diretamente ligada com uma sociedade inclusiva (CARLETTO, 2008).

Já o Desenho Universal para Aprendizagem (Universal Design for Learning - UDL), é um conjunto de princípios baseados na pesquisa e constitui um modelo prático para maximizar as oportunidades de aprendizagem. Os princípios do UDL baseiam-se na pesquisa do cérebro e mídias para ajudar educadores a atingir todos os estudantes, a partir, da adoção de objetivos de aprendizagem adequados, escolhendo e desenvolvendo materiais e métodos eficientes, e modos justos e acurados para avaliar o progresso dos alunos. (ROSE; MEYER, 2002).

Segundo Carletto (2008) em 1997 foram desenvolvidos os Sete Princípios do Design Universal por peritos do Centro de Desenho Universal da Universidade da Carolina do Norte, tendo como foco a concepção, no maior nível possível, de produtos e ambientes utilizáveis por todos os indivíduos sem necessidade de adaptações. São eles: Igualdade, ser útil para pessoas com as mais diversas capacidades; Flexibilidade, acomodar um grande leque de capacidades e preferências individuais; Simples \& Intuitivo, utilização dos produtos e ambientes ser facilmente entendida, independente, da experiência de uso; Percepção \& Informação, comunicação de o produto ser eficaz; Tolerância ao erro, reduzir ao máximo os riscos e consequências adversas das ações dos usuários; Pouco esforço físico, uso dos artefatos de forma eficiente e confortável causando pouca fadiga; Tamanho \& Espaço, proporcionar tamanho e espaço apropriado ao uso independente do corpo, postura ou limitação do usuário.

Através do design universal pode-se preservar a natureza também, pois há possibilidade de criar um artefato que não seja especificamente voltado para um único público-alvo, mas que tenha capacidade de adaptar-se ao maior número possível de consumidores. Já a Tecnologia Assistiva tem foco no desenvolvimento de projetos direcionados principalmente para crianças e/ou adultos com deficiências ou limitações.

\subsection{Tecnologia assistiva}

A Tecnologia Assistiva é um termo bastante recente, que tem como objetivo propiciar à criança ou adulto com deficiência e/ou limitações, recursos e serviços que proporcionem uma maior qualidade de vida, que atendam às suas respectivas necessidades e que ao mesmo tempo auxiliem na sua reabilitação, tornando-se uma grande aliada, para os profissionais da saúde, através de produtos e recursos disponibilizados, que foram projetados especificamente para esse público. Assim, promover uma vida com independência e inclusão na sociedade é a prioridade.

Baseados nos critérios do ADA - American with Disabilities Act, os autores Cook; 
Hussey (1995) definem Tecnologia Assistiva como "uma ampla gama de equipamentos, serviços, estratégias e práticas concebidas e aplicadas para minimizar os problemas funcionais encontrados pelos indivíduos com deficiências".

A Tecnologia Assistiva é uma área voltada totalmente para o usuário e não um recurso do profissional ou de algum campo de trabalho de atuação específica e está diretamente interligada em diversas outras áreas, tornando-se um tema transdisciplinar, envolvendo profissionais como educadores, engenheiros, arquitetos, designers, terapeutas ocupacionais, fonoaudiólogos, fisioterapeutas, médicos, assistentes sociais, psicólogos, entre outros. A acessibilidade também envolve equipe multidisciplinar e diz respeito às condições de autonomia. (COOK; HUSSEY, 1995)

\subsection{Acessibilidade}

O termo acessibilidade define que toda pessoa portadora de deficiências e/ou mobilidade reduzida tenha possibilidade e condições, com segurança e autonomia, de utilizar espaços mobiliários, urbanos, de edificações, de transportes e de sistemas de comunicação. (BRASIL, 2000; LAMÔNICA et al., 2008).

Em decorrência da legislação brasileira, toda pessoa, incluindo as que apresentam deficiências, devem ter acesso garantido, no que diz respeito à educação, à saúde, ao lazer e também ao trabalho. Andrade et al. (2007) corroboram com essa afirmação, pois, descrevem que os indivíduos devem ser percebidos com igualdade e com isso, devem receber atendimento e reconhecimento das suas específicas necessidades.

Conforme Lamônica et al. (2008), ao serem assegurados por lei, as pessoas com deficiências têm seus direitos e os mesmos necessitam ser respeitados, pois, a acessibilidade defende o conceito de cidadania. Porém, segundo Manzini et al. (2003) as barreiras sociais e também as arquitetônicas dificultam esses direitos mais complicados de serem atingidos, pois, somente um espaço construído acessível a todos pode proporcionar oportunidades iguais aos seus usuários, conforme, Bittencourt et al. (2004).

Assim, refletir sobre as barreiras físicas que causam dificuldades as pessoas com deficiências é de extrema importância, porque, propõe o repensar de práticas, propostas e ações que podem melhorar a qualidade de vida e promover a saúde destas pessoas.

\subsection{Inovação Social}

Ao introduzir novidade ou aperfeiçoamento em ambientes de produção e/ou sociais, gerando novos produtos, processos ou serviços há inovação, segundo a Lei 10.973/04 - Lei da Inovação.

Conforme Manzini (2008), há também um tipo de inovação, chamada social, que se refere à criação de novos conceitos, estratégias e organizações que permitam a inclusão social através de produtos, processos e serviços, o que propicia uma maior qualidade de vida e atende as pessoas que possuem necessidades sociais de todos tipos. Inovação social diz respeito às mudanças na forma de resolução de problemas 
e criação de novas oportunidades e suas mudanças. Sendo que, tais inovações têm maior foco nas mudanças comportamentais em detrimento das tecnológicas ou de mercado. A inovação social atua no campo das relações e ações sociais e pode tornar-se o ponto de partida para transformações sociais e modelo de desenvolvimento econômico, ao modificar a percepção de organizações, empresas, governos e indivíduos na sociedade. A reflexão e a discussão dos conceitos básicos e teóricos da inovação social estão tornando-se crescentes, dentro e fora da academia.

\subsection{Leis, decretos e requerimento}

A Lei de Cotas para Deficientes e Pessoas com Deficiência dispõe sobre os Planos de Benefícios da Previdência e dá outras providências com relação a contratação de portadores de necessidades especiais. Assim, fica decretado que uma empresa com 100 ou mais funcionários está obrigada a preencher um percentual dos seus cargos com beneficiários reabilitados, ou pessoas portadoras de deficiência na determinada proporção: Empresas com até 200 funcionários - 2\%; Empresas de 201 a 500 funcionários - 3\%; de 501 a 1000 funcionários - 4\%; de 1001 em diante funcionários $-5 \%$.

Segundo o Requerimento de Informações № 81 (2013), a lei de cotas é de 1991 e foi regulamentada em 1999. Um dos motivos da demora para a regulamentação foi o próprio conceito de deficiência - considerado atualmente a perda ou a anormalidade de uma estrutura ou função psicológica, fisiológica ou anatômica. A fiscalização das cotas só teve início em 2001 pelas Delegacias Regionais de Trabalho (DRTs) que conscientizam, fiscalizam e notificam as empresas para garantir o cumprimento da Lei. Apenas a partir do exposto, as empresas ampliaram sua preocupação com o assunto. Além da responsabilidade social pesou a ameaça pecuniária. A multa aplicada às empresas que não cumprem a legislação é pesada, ou seja, a empresa que descumprir a Lei 8.213/91, quando autuada, pode pagar uma multa que varia de $\mathrm{R} \$ 1.195,13$ a R\$119.512,33 conforme a Portaria 1.199 de 28 de outubro de 2003.

No decreto № 5.296/04 em seu Art. 61 considera-se ajuda técnica produtos, instrumentos, equipamentos ou tecnologias, adaptadas ou especificamente projetadas, para melhorar a funcionalidade da pessoa portadora de deficiência ou com limitações, assim, favorecendo a autonomia pessoal, total ou assistida. No Art. 80, para os fins de acessibilidade, considera-se o termo como condição para utilização, com segurança e autonomia, total ou assistida, dos espaços, mobiliários e equipamentos urbanos, das edificações, dos serviços de transporte e dos dispositivos, sistemas e meios de comunicação e informação, por pessoa portadora de deficiência ou com mobilidade reduzida.

\section{Análise dos dados}

O presente estudo foi realizado através de três etapas: $A, b$ e c , onde, ao analisar a Revista Estudos em Design, a partir da edição de 2007 até 2015, identificou-se um total de 137 artigos, conforme Tabela 1. Com relação as edições especiais da Revista, a única que edição especial que foi analisada nesta pesquisa foi a do 15 ERGODE- 
SIGN e USIHC no ano de 2015, por se tratar de uma área próxima da pesquisa. Na tabela pode-se perceber que de todas as publicações analisadas, foram encontrados somente quatro artigos que atenderam os requisitos especificados no item 2 (Objetivos e métodos), sendo que um deles aborda o tema Tecnologia Assistiva, dois dizem respeito à Acessibilidade e dois sobre o Design Universal (sendo que um deles não foi contabilizado, pois já havia sido computado nos artigos referentes a Acessibilidade).

\begin{tabular}{ccccc} 
Ano de Publicação & Artigos Publicados & Tecnologia Assistiva & Acessibilidade & Design Universal \\
2015 & 25 & $X$ & $X$ & $X$ \\
2014 & 23 & & & \\
2013 & 20 & & \\
2012 & 13 & & \\
2011 & 10 & & \\
2010 & 20 & & \\
2009 & 8 & 1 & 1 \\
2008 & 9 & & \\
2007 & 9 & & \\
\hline Total & 137 & & \\
&
\end{tabular}

Conforme o Gráfico 1, com relação aos anos em que foram publicados os artigos, pode-se perceber que 2010, 2013, 2014 e 2015 tiveram o maior número de publicações. Sendo que, dos quatro artigos que se enquadraram no tema dessa pesquisa um foi publicado em 2013 e os outros três em 2015. Com isso pode-se perceber que artigos sobre este tema estão em ascensão.

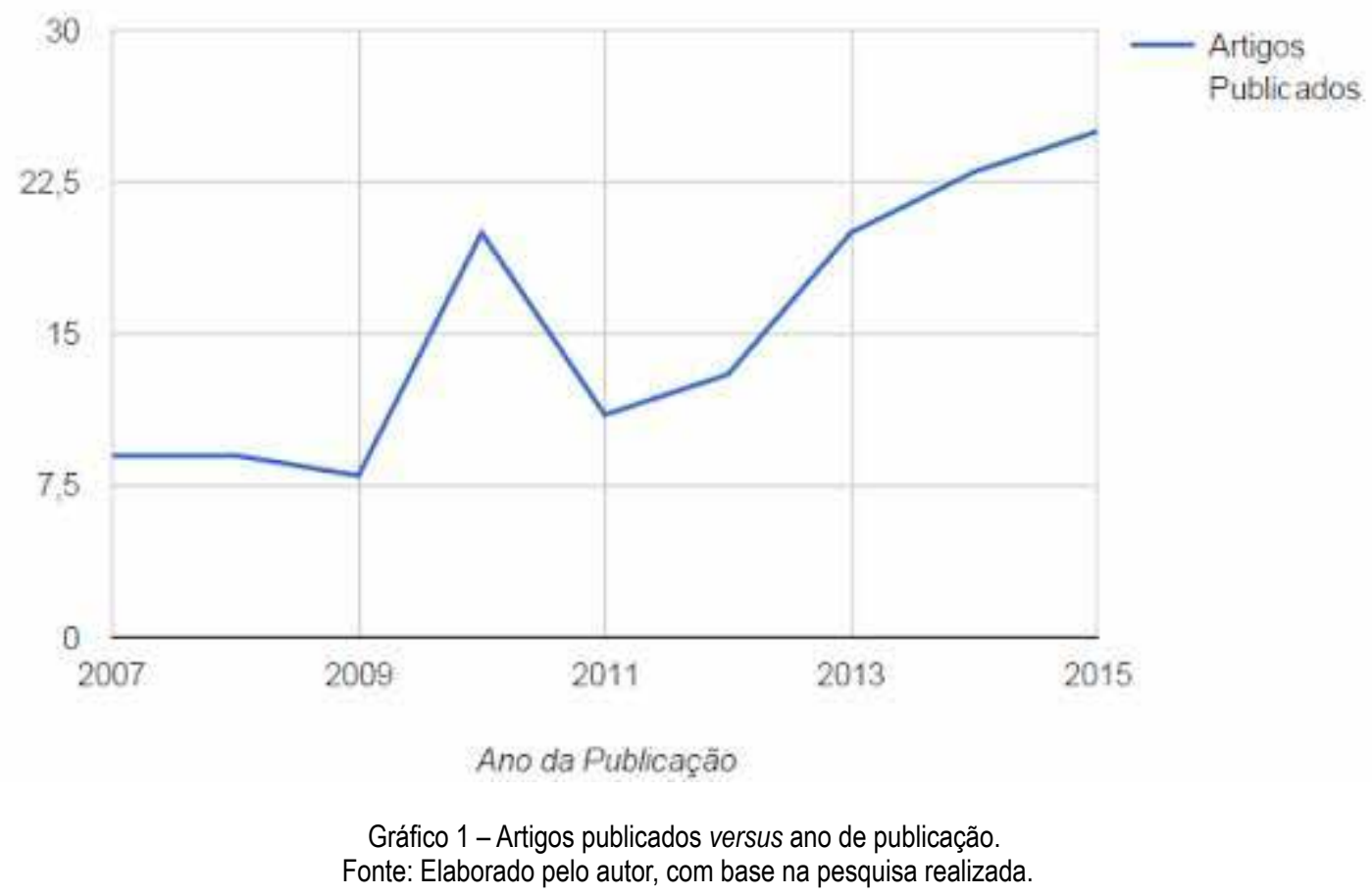

Sobre as Instituições de Ensino Superior (IES), pode-se visualizar as que mais elaboraram artigos publicados na Tabela 2. Muitas das publicações não têm a Institui- 
ção identificada, neste caso são 27 , mas no caso das identificadas, pode-se averiguar que aquelas que têm maior número de publicações são, respectivamente, a UFSC (Universidade Federal de Santa Catarina), seguida da PUC-RIO (Pontifícia Universidade Católica do Rio de Janeiro) e da UFPR (Universidade Federal do Paraná).

\begin{tabular}{cc|cc} 
Instituição Origem & Artigos & Instituição Origem & Artigos \\
UFSC & 16 & Alßan & 1 \\
PUC-RIO & 14 & ANHEMBI & 1 \\
UFPR & 11 & UTL & 1 \\
UFPE & 9 & UNISUL & 1 \\
UNESP & 7 & UFF & 1 \\
UEMG & 7 & UNISINOS & 1 \\
UFRGS & 6 & UFSM & 1 \\
SENAC & 3 & CEFETSC & 1 \\
UFV & 3 & SEVILLA & 1 \\
UFMA & 3 & EDI & 1 \\
USP & 3 & UFES & 1 \\
UniRitter & 3 & POSITIVO & 1 \\
UFMG & 2 & ESPM & 1 \\
UFBA & 2 & FTEC & 1 \\
UEL & 2 & UFRJ & 1 \\
UNIVILLE & 2 & FOC & 1 \\
UERJ & 1 & IFSC & 1
\end{tabular}

Tabela 2 - Instituições de Ensino Superior e suas publicações. Fonte: Elaborado pelo autor, com base na pesquisa realizada.

Conforme análise dos dados pode-se notar que a grande maioria das IES de Design do país publicou apenas um artigo na Revista, sendo algumas delas: UERJ, UTL, Anhembi, UFF, UFSM, Escola Superior de Design (ESD), Unisinos, ESPM, IFSC, UFRJ, FTEC, entre outras. O Estado do Rio Grande do Sul, através de suas Instituições, publicou um total de 11 artigos. Através desses resultados, pode-se concluir que publicações sobre os temas Tecnologia Assistiva, Acessibilidade e Design Universal podem ser bastante relevantes, devido ao número reduzido de estudos publicados na área e principalmente no Estado do Rio Grande do Sul.

Entre todos os artigos analisados (tabela 3), apenas quatro se enquadraram nas características que o tema desta pesquisa propõe. Pode-se afirmar que dois deles foram elaborados pelas Universidades que mais publicaram artigos na Revista Estudos em Design, a saber, UFSC e UFPR, cabe ressaltar que os artigos são bastante recentes, sendo os dois do ano de 2015. Os outros artigos selecionados foram publicados pela UNESP no ano de 2013 e UFSM em 2015.

O primeiro artigo avaliado foi publicado na Revista pela UNESP em 2013, sendo os autores Alonso y Alonso Guazzelli, Ruffato Resende, Giunta da Silva e Anchieta Messias. O estudo tem por objetivo contribuir para a promoção do conceito de acessibilidade aplicado às edificações de uso coletivo no município de Presidente Prudente, através de leituras arquitetônicas e urbanísticas e também foi descrito sobre à exclusão sócio-espacial, o Desenho Universal. Esta pesquisa utiliza-se de dois termos 
chave, que foram eleitos no presente estudo, em razão disso, foi computado apenas uma vez este artigo.

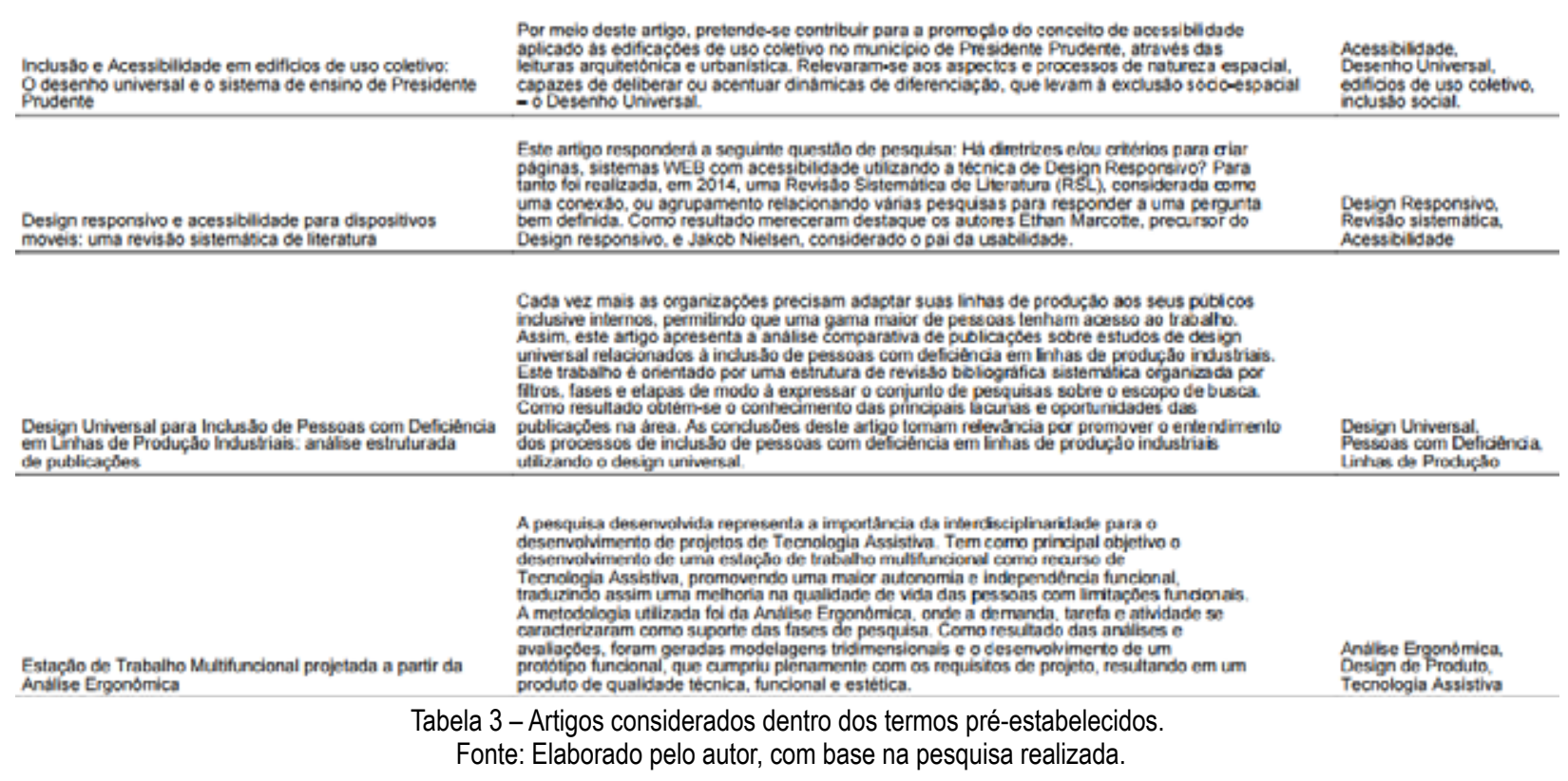

Já o segundo é uma pesquisa realizada por Ribas, Vanzin e Ulbricht, em 2015, porém com volume $23, \mathrm{n}-3$. O objetivo era verificar através de plataformas como a Capes, Scopus, Biblioteca UFSC e Scielo a busca pelos termos Design Responsivo, Usabilidade, Acessibilidade e Dispositivos Móveis, a Universidade que publicou este artigo foi a UFSC.

O terceiro artigo analisado é um estudo bibliográfico que avaliou as publicações de periódicos internacionais, referindo-se a pesquisas nos temas Design Universal, Pessoas com Deficiência e Linhas de Produção de autoria de Teixeira, Okimoto e Heemann no ano de 2015 volume 23, no 2 pela UFPR.

O quarto artigo, foi elaborado pela UFSM em 2015 e fala sobre a interdisciplinaridade para o desenvolvimento de projetos de Tecnologia Assistiva, tendo como objetivo o desenvolvimento de uma estação de trabalho multifuncional como recurso de Tecnologia Assistiva.

Com base nos dados coletados, para finalizar a análise, realizou-se um levantamento das palavras-chave utilizadas nos artigos analisados, para criar uma visão geral da frequência de termos. Verificou-se que as palavras mais utilizadas nos trabalhos foram: design (90 ocorrências), seguido de ergonomia (19), produto (16), projeto (10), usabilidade (7), conhecimento (6), entre outras.

Para uma melhor visualização dos dados, as palavras-chaves foram separadas e organizadas para serem inseridas em um programa computacional, que analisa a frequência de repetição das palavras. Com isso, aquelas que obtiveram maior aplicação entre os artigos são as que aparecem em maior tamanho na nuvem de palavras. $\mathrm{Na}$ Figura 1, pode-se analisar os resultados obtidos, no qual a nuvem de palavras foi elaborada retirando a palavra design para fins de visualização mais aprofundada das demais palavras analisadas. 


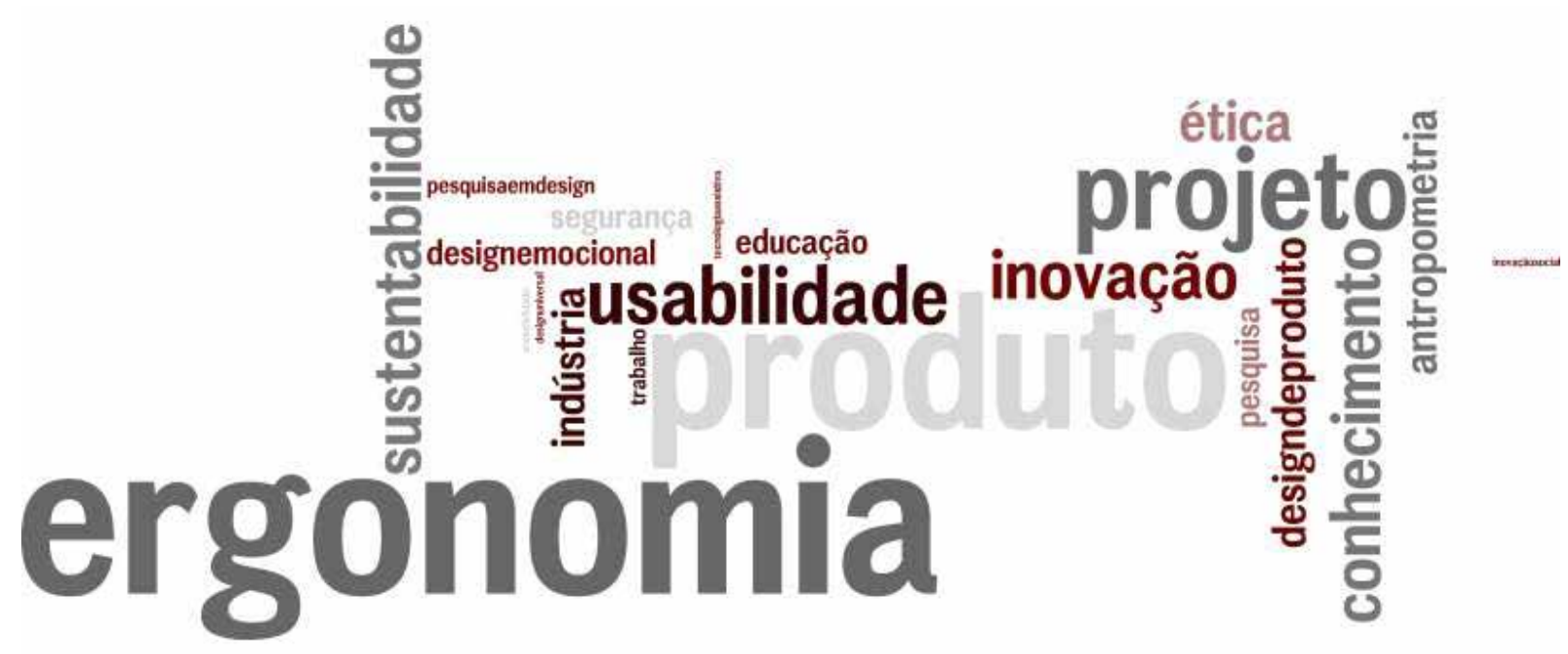

Figura 1 - Compilação das palavras-chave, excluindo a palavra design, mais utilizadas nos artigos analisados. Fonte: Elaborado pelo autor, com base na pesquisa realizada.

Através dos resultados obtidos com esta pesquisa, pode-se perceber as publicações da mesma foram minoria entre os anos de 2007 e 2009 e tiveram um crescimento nos anos de 2010. 2013, 2014 e 2015, sendo que em 2013 e 2015, foram computadas quatro publicações que se encaixaram na busca da presente pesquisa. Os artigos que se enquadram, foram desenvolvidos por duas das IES que mais publicaram dentre os anos analisados da Revista, a saber UFSC e UFPR e também pela UNESP e pela UFSM. Por fim, as palavras-chave mais frequentemente utilizadas pelos autores foram principalmente design, seguido de ergonomia, produto e projeto.

\section{Considerações finais}

No atual contexto social, a inclusão está sendo cada vez mais percebida pelas organizações, pois, as mesmas entenderam a importância de ter o conhecimento sobre essas questões, com o objetivo de auxiliar a rotina dos seus funcionários, proporcionando-lhes uma forma digna e merecida de trabalhar, com um ambiente adequado as suas necessidades.

Através dos dados encontrados nesta pesquisa e dos resultados analisados, pode-se obter um panorama geral das publicações em Tecnologia Assistiva, Acessibilidade e Design Universal em uma Revista de Design muito conceituada nacionalmente. Com este estudo verificou-se o que a quantidade de publicações nos últimos anos na área do Design em geral, demonstrando assim, os anos com maior e menor número de publicações.

Sobre as IES, a UFSC é a campeã de em relação aos artigos publicados, seguida da PUC-RIO e da UFPR. Cabe salientar que as IES que mais publicam na Revista são de Estados distintos, Santa Catarina, Rio de Janeiro e Paraná, porém, duas delas são da mesma região do país, o Sul.

No que diz respeito a metodologia utilizada, este estudo pode contribuir para pesquisas futuras que poderão utilizar-se deste tipo de método para realizar traba- 
lhos de áreas correlatas ou diversas. Para um trabalho futuro sugere-se uma análise aprofundada em outras bases de dados específicas da área do design, como também em trabalhos de conclusão de curso, dissertações e teses, de forma à complementar este estudo.

Por fim, este trabalho deseja propor discussões e/ou caminhos de pesquisas com a intenção de contribuir e fomentar estudos no meio acadêmico científico ou mesmo organizacional sobre os assuntos debatidos, pois, a inclusão através da Tecnologia Assistiva, da Acessibilidade e do Design Universal é de extrema importância para a sociedade e para o sucesso das empresas que contratam os PCD's, e consequentemente promovem o respeito e a integração dos mesmos de forma igualitária.

\section{Referências}

ANDRADE, M. S. A. et.al. Pessoas com deficiência rumo ao processo de inclusão na educação superior. Revista Digital de Pesquisa CONQUER da Faculdade São Francisco de Barreiras, vol. 1, 2007.

BERSCH, Rita. Tecnologia Assistiva. Brasil, 2014. Disponível na internet por http em: <http://www.assistiva.com.br/tassistiva.html>. Acesso em 23 dez. 2015.

BITTENCOURT, L. S. et. al. Acessibilidade e Cidadania: barreiras arquitetônicas e exclusão social dos portadores de deficiência física. Anais do $2 \circ$ Congresso Brasileiro de Extensão Universitária, 2, Belo Horizonte, 2004. Anais. Belo Horizonte, 2004.

BRASIL. Lei n․ 10098 de 19 de dezembro de 2000. Estabelece normas gerais e critérios básicos para a promoção da acessibilidade das pessoas portadoras de deficiência ou com mobilidade reduzida, e dá outras providências.

BRASIL. Lei no 8213 de 24 de Julho de 1991. Dispõe sobre os Planos de Benefícios da Previdência Social e dá outras providências.

BRASIL. Decreto no 5.296 de 02 de Dezembro de 2004. Regulamenta as Leis nos 10.048 , de 8 de novembro de 2000, que dá prioridade de atendimento às pessoas que especifica, e 10.098, de 19 de dezembro de 2000, que estabelece normas gerais e critérios básicos para a promoção da acessibilidade das pessoas portadoras de deficiência ou com mobilidade reduzida, e dá outras providências.

BRASIL. Requerimento de Informação no 81 de 2013. Nos termos do artigo 20, inciso XVI da Constituição do Estado de São Paulo, combinado com o artigo 166 da XIV Consolidação do Regimento Interno.

BRASIL. Lei no 10.973 de 02 de Dezembro de 2004. Ela dispõe incentivos à inovação e à pesquisa científica e tecnológica no ambiente produtivo e dá outras providências. 
CARLETTO, Ana Claudia, CAMBIAGHI, Silvana. Desenho Universal: um conceito para todos. São Paulo: Instituto Mara Gabrilli, 2008.

COOK, A.M; HUSSEY, S. M. (1995) Assistive Technologies: Principles and Practices. St. Louis, Missouri. Mosby - Year Book, Inc.

GIL, Antônio Carlos. Como elaborar projetos de pesquisa. São Paulo: Atlas, 2010.

LAKATOS, Eva Maria et. al. Fundamentos de metodologia científica. 7 ed. São Paulo: Atlas, 2010.

LAMÔNICA, D. A. C et al. Acessibilidade em ambiente universitário: identificação de barreiras arquitetônicas no campus da USP de Bauru. Rev. Bras. Educ. Espec. v.14, n.2, p. 177-188, 2008.

MANZINI, E. J. et al. Acessibilidade em ambiente Universitário: identificação e quantificação de barreiras arquitetônicas. In: MARQUEZINI, M. C. et al. (Org.).

MANZINI, Ezio. Design para a inovação social e sustentabilidade: comunidades criativas, organizações colaborativas e novas redes projetuais. Rio de Janeiro: E-papers, 2008.

MOREIRA, Bruna Ruschel; COSTA, Filipe Campelo Xavier da. Do objeto ao contexto estratégico: a evolução do entendimento do conceito de Design e seu desenvolvimento metodológico. In: Anais do 9o Congresso Brasileiro de Pesquisa e Desenvolvimento em Design. São Pulo, 2010.

MOURA, Mônica; GUSMÃO, Cláudio. O Design no trânsito entre a criação e a tecnologia. Design, Arte e tecnologia - vol. 4. p. 6. São Paulo: Rosari, 2008.

MÜLLER, Mauro Adriano. O Design Universal. Disponível na internet por http em: <http://www.revistacliche.com.br/2013/04/o-design-universal/>. Acesso em 14 dez. 2015.

Rose, D. H.; Meyer, A. (Eds.). (2006). A practical reader in Universal Design for Learning. Cambridge, MA: Harvard Education Press.

TEIXEIRA, Edson Sidnei Maciel et. al. Design Universal para Inclusão de Pessoas com Deficiência em Linhas de Produção Industriais: análise estruturada de publicações. Estudos em Design | Revista (online). Rio de Janeiro: v. 23 | n. 2 [2015], p. 133. 